\title{
Spatial mapping of root systems reveals diverse strategies of soil exploration and resource contest in grassland plants
}

DOI:

10.1111/1365-2745.13535

\section{Document Version}

Accepted author manuscript

Link to publication record in Manchester Research Explorer

Citation for published version (APA):

Lepik, A., Abakumova, M., davison, J., Zobel, K., \& Semchenko, M. (2020). Spatial mapping of root systems reveals diverse strategies of soil exploration and resource contest in grassland plants. Journal of Ecology, 109(2), 652-663. https://doi.org/10.1111/1365-2745.13535

\section{Published in:}

Journal of Ecology

\section{Citing this paper}

Please note that where the full-text provided on Manchester Research Explorer is the Author Accepted Manuscript or Proof version this may differ from the final Published version. If citing, it is advised that you check and use the publisher's definitive version.

\section{General rights}

Copyright and moral rights for the publications made accessible in the Research Explorer are retained by the authors and/or other copyright owners and it is a condition of accessing publications that users recognise and abide by the legal requirements associated with these rights.

\section{Takedown policy}

If you believe that this document breaches copyright please refer to the University of Manchester's Takedown Procedures [http://man.ac.uk/04Y6Bo] or contact uml.scholarlycommunications@manchester.ac.uk providing relevant details, so we can investigate your claim.

\section{OPEN ACCESS}


1 Spatial mapping of root systems reveals diverse strategies of

2 soil exploration and resource contest in grassland plants

3

4

5

6

$7 \quad$ Estonia

8

9

10

11

12

13

14

15

16

17

18

19

20

21

22

23 Estonia 1

Anu Lepik1, Maria Abakumova1 ${ }^{1}$, John Davison'1, Kristjan Zobel1, Marina

Semchenko ${ }^{2 *}$

${ }^{1}$ Institute of Ecology and Earth Sciences, The University of Tartu, Lai 40, 51005, Tartu,

2 Department of Earth and Environmental Sciences, Michael Smith Building, The University of Manchester, Oxford Road, Manchester M13 9PT, UK

* Author for correspondence: marina.semchenko@manchester.ac.uk

Running title: Spatial behaviour of plant roots

Article type: research article

\section{Word counts:}

Main body - 5426; Abstract - 245; Introduction - 1310; Materials and Methods - 1956;

Results - 638; Discussion - 1525; Number of figures - 5; Number of tables - 2

\section{Author contributions}

MS and KZ designed the study; AL, MA, MS and KZ carried out the study; MS and JD analysed the data; AL and MS wrote the first draft of the manuscript and all authors contributed to revisions.

\section{Data accessibility}

Should the manuscript be accepted, the data supporting the results of this study will be archived in Figshare, and the data DOI will be included at the end of the article. 


\section{Abstract}

1. When foraging and competing for belowground resources, plants have to coordinate the behaviour of thousands of root tips in a manner similar to that of eusocial animal colonies. While well described in animals, we know little about the spatial behaviour of plants, particularly at the level of individual roots.

2. Here, we employed statistical methods previously used to describe animal ranging behaviour to examine root system overlap and the efficiency of root positioning in eight grassland species grown in monocultures and mixtures along a gradient of neighbour densities.

3. Species varied widely in their ability to distribute roots efficiently, with the majority of species showing significant root aggregation at very fine spatial scales. Extensive root system overlap was observed in species mixtures, indicating a lack of territoriality at the level of whole root systems. However, with increasing density of competitors, several species withdrew roots from the periphery of foraging ranges and increased intraplant root aggregation in the remaining area, which may indicate consolidation of foraging areas under competitive pressure.

4. Several species exhibited responses consistent with resource contest in species mixtures where encounters with competitors' roots triggered increased root aggregation at the expense of foraging efficiency. Such responses only occurred in mixtures of species with comparable competitive abilities but were absent in asymmetric species combinations.

5. Synthesis. Combining fine-scale measurement of plant root distributions with spatial statistics yields new insights into plant behavioural strategies with significant potential to impact resource foraging efficiency and productivity. 
49 Key words: belowground interactions, competition, foraging efficiency, functional traits,

50 ideal free distribution, plant behaviour, plant-plant interactions, root spatial

51 distribution, root system overlap

52 
53

54

55

56

57

58

59

60

61

62

63

64

65

66

67

68

69

70

71

72

73

74

75

76

\section{Introduction}

Plants produce extensive root systems often comprising kilometres of root length and organised in complex branched structures. Due to a lack of easy tools to quantify and characterise root spatial distributions, our knowledge of how roots are distributed in soil at different spatial scales and how spatial patterns change in response to competitive interactions is limited (Semchenko, John, \& Hutchings, 2007b; Cahill et al., 2010; Yang, Li, Xu, \& Kong, 2018). On the other hand, root systems share qualities with certain animals whose foraging and territorial behaviour has been extensively studied, offering new ways of exploring and quantifying plant root behaviour (Novoplansky, 2009; McNickle \& Brown, 2012; Ljubotina \& Cahill, 2019).

Root systems may be comparable to eusocial central-place foragers such as bees and ants, with root tips analogous to highly-related individuals serving the purpose of foraging and delivering resources to a central "nest site", i.e. in plants, the rooting point connected to aboveground tissues. In common with animal colonies, root systems are fundamentally constrained by the necessity to initiate all root growth from a single rooting point (or a few rooting points in the case of clonal plants). Branching patterns further constrain the spatial positioning of higher order branches (Robinson, Hodge, \& Fitter, 2003). In animal systems, a parallel to such constraints may be the use of established paths or tunnels in ant and termite foraging that lead individuals to the most profitable foraging areas (Traniello, 1989; Almeida et al., 2018). Beyond the constraints of shared spatial origin, plant roots are expected to follow the ideal free distribution in the absence of competitors, minimising intraplant competition and maximising resource uptake efficiency (McNickle \& Brown, 2014). Root system modelling indicates that nutrient uptake efficiency is strongly influenced by root system topology and root 
branching angles (Fitter, Stickland, Harvey, \& Wilson, 1991; Ge, Rubio, \& Lynch, 2000; Lynch \& Brown, 2001; Rubio, 2001; Dunbabin, Rengel, \& Diggle, 2004). However, empirical measurements of spatial distributions at the level of individual roots are scarce (Caldwell, Manwaring, \& Durham, 1991, 1996). Furthermore, while knowledge about easily measured root morphological traits, and their links with community- and ecosystem level processes, is rapidly accumulating (Bardgett, Mommer, \& deVries, 2014; Roumet et al., 2016; Kramer-Walter et al., 2016), it is unknown how these traits relate to the efficiency of soil exploration at the level of individual roots. Revealing these relationships could significantly improve our mechanistic understanding of fundamental plant strategies.

Spatial behaviour is strongly influenced by interactions with neighbouring individuals. Animals typically have an area that is regularly traversed in search of resources (food and/or mates), known as the home range, which may be shared with other groups or individuals (Adams, 2001). Depending on the costs of conflict and the benefits of acquiring resources, different strategies are optimal, and different patterns of home range overlap emerge (Sih \& Mateo, 2001; Morrell \& Kokko, 2005; Börger, Dalziel, \& Fryxell, 2008). When the cost of aggressive contest is very high and population densities relatively low, the strategy of avoiding contest and seeking empty space is most successful, leading to largely segregated home ranges (Stamps \& Krishnan, 2001; Morrell \& Kokko, 2005). In plants, this scenario matches most closely to arid and semiarid ecosystems or communities with low densities of individuals where root system segregation has indeed been recorded (Brisson \& Reynolds, 1994; Schenk, Callaway, \& Mahall, 1999). When the costs of aggression are very low, the boldest and most aggressive strategy is predicted to prevail, as the cost of sharing space is too low to deter individuals from revisiting the same sites (Carpenter, 1987; Morrell \& Kokko, 2005). 
This scenario fits observations from mesic grasslands and forests where root systems tend to overlap extensively (Fitter, 1987; Mamolos, Elisseou, \& Veresoglou, 1995; Lang, Dolynska, Finkeldey, \& Polle, 2010; Mommer et al., 2010; Laclau et al., 2013, McNickle \& Brown, 2014). Furthermore, the degree of asymmetry among individuals in their capacity to inflict damage (e.g. due to difference in size or resource uptake efficiency) is expected to affect the outcome of interactions, leading to escalation or stalemate between individuals of similar ability but unidirectional attack and escape when individuals have asymmetric abilities (e.g. interspecific competition; Stamps \& Krishnan, 2001; McNickle \& Brown, 2012). The applicability of this theory to plants remains to be tested.

Both theoretical predictions as well as empirical observations of plant root systems have primarily focused on estimating total root production and root system overlap at large spatial scales (Brisson \& Reynolds, 1994; reviewed in Schenk et al., 1999; Gersani, Brown, O’Brien, Maina, \& Abramsky, 2001; Maina, Brown, \& Gersani, 2002; Holzapfel \& Alpert, 2003; 0’Brien, Brown, \& Moll 2007; Semchenko, Hutchings, \& John, 2007a; Cahill et al., 2010; McNickle \& Brown, 2014). Spatial positioning of individual roots has rarely been measured (Mahall \& Callaway, 1991, 1992; Caldwell et al., 1991, 1996; Semchenko et al., 2007b) but could significantly improve our understanding of resource foraging efficiency in plants and provide a new perspective on plant behavioural strategies such as resource contest and conflict avoidance. In this study, we revisited the technique of freezing intact soil and mapping root spatial locations (Caldwell et al., 1991, 1996) and combined it with georeferencing software and statistical methods used to describe animal foraging and home range behaviour. Using these tools, we explored root spatial distributions in a range of temperate grassland species that were subjected to varying densities of conspecific and 
heterospecific competitors. We expected that roots belonging to the same individual would be aggregated at small spatial scales, indicating low efficiency of soil exploration, due to the intrinsic constraints of central-place foraging, but the degree of root aggregation would vary among species as a function of architecture (Fitter et al., 1991; Dunbabin et al., 2004; Ge et al., 2000; Lynch \& Brown, 2001; Rubio, 2001) and root system size, with larger root systems less efficient at space exploration (Berntson, 1994; Pagès, 2011). At larger spatial scales, we expected root systems to be more flexible and therefore more likely to occupy space evenly (Gersani, Abramsky \& Falik, 1998; McNickle \& Brown, 2014; Yang et al., 2018).

We also expected root spatial distribution to vary as a function of species competitive ability. It has been predicted that combinations of individuals with contrasting competitive abilities should produce lower root biomass compared with mixtures comprising similar competitors (e.g. conspecifics), where escalating overproliferation is likely (McNickle \& Brown, 2012). However, no predictions have been made regarding the efficiency of root placement. We suggest that escalating resource contest among species with similar competitive abilities (reflected in the similar biomass of competitors) may be manifested at fine spatial scales as aggregation of competitors' roots and hence low efficiency of soil exploration. On the other hand, interactions between species with contrasting competitive abilities may increase intraplant root aggregation in competitively inferior species as a means of defending their limited home ranges. Root positioning was recorded at two soil depths, to assess the consistency of patterns along the soil profile, and at a range of neighbour densities to explore how interactions changed with increasing competitive pressure. Lastly, we related root spatial distribution and home range patterns to root morphological traits in order to integrate root spatial behaviour with traits commonly used to describe plant 
belowground strategies. We predicted that species with root traits reflecting a competitive strategy, such as high specific root length and low tissue density (Wang, Stieglitz, Zhou, \& Cahill, 2010; Ravenek et al., 2016; Semchenko, Lepik, Abakumova, \& Zobel, 2018), would engage in resource contest by aggregating roots in the vicinity of competitors. On the other hand, species with traits reflecting alternative resource acquisition strategies, such as association with mycorrhizal fungi (e.g. reduced root branching and large root diameter; Semchenko et al., 2018; Bergmann et al., 2020), were predicted to exhibit efficient root placement and avoid neighbours' roots.

\section{Materials and methods}

\section{Experimental design and measurements}

The seeds of eight plant species (Antennaria dioica (L.) Gaertn., Carlina vulgaris L., Filipendula vulgaris Moench., Galium verum L., Lotus corniculatus L., Pilosella officinarum Vaill., Pimpinella saxifraga L., Sesleria caerulea (L.) Ard.) were collected in 2008 from a semi-natural, calcareous (alvar) grassland in Estonia $\left(58^{\circ} 38^{\prime} 31^{\prime \prime} \mathrm{N}, 23^{\circ} 30^{\prime} 55^{\prime \prime} \mathrm{E}\right)$. The site is characterised by high species richness and rendzic leptosol soil type, with an average of $18 \mathrm{~cm}$ of humus layer over limestone shingle parent material (Pärtel, Kalamees, Zobel, \& Rosen, 1999; Nettan, Thetloff, Lepik, Semchenko, \& Zobel, 2019). The seeds were airdried and stored at $4^{\circ} \mathrm{C}$. The following spring, seeds were germinated on moist sand, and similar-sized seedlings were transplanted into $3.5 \mathrm{l}$ pots $(17.1 \mathrm{~cm}$ diameter, $15 \mathrm{~cm}$ deep) filled with a mixture of commercial potting compost (pH 6, water-soluble $\mathrm{N} 100 \mathrm{mg} / \mathrm{l}, \mathrm{P}$ $80 \mathrm{mg} / \mathrm{l}, \mathrm{K} 400 \mathrm{mg} / \mathrm{l}$ ), sand and limestone powder. The germination of seeds from different species was timed such that seedlings were available for transplantation at the same time. The soil mixture was prepared to match the $\mathrm{pH}$ and $\mathrm{N}$ content of the soil at 
the seed collection site as closely as possible. To provide plants with natural soil biota, soil from the site of seed collection was also added to the mixture. Each species was grown surrounded by either conspecific or heterospecific neighbours (species monoculture and mixture treatments, respectively). Distributing experimental replicates along a continuous gradient of environmental treatment with little or no replication per treatment level can provide a more powerful approach for identifying responses to environmental variation than examining fewer replicated levels of an environmental treatment (Kreyling et al., 2018). Therefore, rather than employing the frequently used approach of growing plants alone and at an arbitrary neighbour density, we exposed plants to a gradient of seven neighbour densities (no neighbours, 1, 2, 3, 4, 6 or 8 neighbours) to obtain robust estimates of root spatial patterns and their responses to neighbour density. The focal plant was planted at the centre of each pot and neighbouring individuals were planted in a circle, equidistant from each other and at 5.7 $\mathrm{cm}$ distance from the focal plant (corresponding to $2 / 3$ of the pot radius). Each focal species was grown in the mixture treatment with a species that it frequently encounters as its nearest neighbour in the field (Semchenko, Abakumova, Lepik, \& Zobel, 2013). Each focal species $\times$ neighbour density (1-8) combination was replicated twice and focal plants grown in the absence of neighbours were replicated four times (224 pots in total; 212 measured at harvest due to seedling mortality).

Pots were placed randomly in a common garden at the end of May 2009 and rerandomised twice during the experiment. Plants received natural precipitation and additional watering during dry spells and were harvested after 14 weeks of growth. Aboveground biomass was removed and dried at $70^{\circ} \mathrm{C}$ for $48 \mathrm{~h}$ and weighed. The roots were left intact in the soil, which was then frozen at $-18^{\circ} \mathrm{C}$. The frozen pots were sliced horizontally at depths of $5 \mathrm{~cm}$ and $10 \mathrm{~cm}$ below the soil surface. Roots were mapped at 
two depths to determine if patterns of variation in root spatial distributions were similar across different depths. The surfaces of defrosted soil slices were gently cleared with water, to expose roots that had been sliced through, and scanned (Epson perfection V700 PHOTO, Long Beach, CA, USA). The locations of all root intersections visible within the central area of the scanned image, corresponding to $2 / 3$ of the pot radius (Figs. 1 and S1 in Supporting Information), were recorded using ArcGiS software (version 10.0, ESRI, Aylesbury, UK). The species examined in the mixture treatment had different root colours, allowing focal and neighbouring plant roots to be visually distinguished; in the species monoculture treatment, focal and neighbouring plant roots were not distinguished. Hence, analysis of spatial patterns in monocultures was performed across all plants in the pot while analysis of mixture data was performed for focal individuals and neighbours separately.

To relate root spatial patterns to root morphology and architecture, we used root trait data presented in Semchenko et al., 2018. These data were collected from the same experiment, following the scanning of the soil slices by carefully washing roots out from the top soil slices (0-5 cm depth) and separating the roots of focal and neighbouring plants. From each focal plant and its neighbours, two representative root axes were selected randomly for root morphological analysis. Roots were scanned (Epson perfection V700 PHOTO, Long Beach, CA, USA), dried at $70^{\circ} \mathrm{C}$ for $48 \mathrm{~h}$ along with all of the remaining roots and weighed. Root diameter, root length, root volume, and the number of root tips were calculated using the program WinRhizo 2008a (Regent Instruments Inc., Quebec, Canada). Using these measurements, root tissue density (dry root mass/root volume), specific root length (root length/dry root mass), and root branching frequency (number of root tips/root length) were calculated. 
227

228

\section{Intraspecific root spatial distribution}

The degree of root spatial aggregation or segregation was calculated for each pot and soil depth using the L function, which is derived by comparing Ripley's K function to the pattern expected under complete spatial randomness (Ripley, 1976; Rowlingson \& Diggle, 2017). Ripley's K function $(\mathrm{K}(t))$ is defined as the expected number of additional points within a distance $t$ of an arbitrary point within the study area, divided by the overall density of points and corrected for edge effects. The L function was calculated as: $\mathrm{L}(t)=\operatorname{sqrt}(\mathrm{K}(t) / \pi)-t$. The value of the function is zero if points are distributed randomly in space (suggesting no response to the presence of neighbouring roots), negative if points are overdispersed (indicative of root segregation and high efficiency of space exploration), and positive if points are spatially aggregated (indicative of low efficiency of soil exploration; Fig. 1). The L-function was calculated across all plants for species monocultures and at the level of individual focal plants (i.e. reflecting intra-plant spatial patterns) and neighbours for species mixtures. In this analysis, points represented the locations of root intersections. Since the density of roots from a single individual declines with distance from the rooting point and pots contained multiple individuals, root density varied strongly across the pot, violating the assumption of homogeneity that underpins the standard Ripley's K calculation (i.e. that the mean intensity of the point pattern is constant across the observation area). To account for variation in rooting densities across the pot, we used a generalisation of the $\mathrm{L}$ function for inhomogeneous point patterns, which estimates the local intensity of the point pattern using "leave one out" kernel smoothing (standard deviation of the Gaussian kernel estimated based on the size of the observation area), with "translation" edge correction, (function Linhom from R package spatstat, Baddeley, Rubak, \& Turner, 2015). 
251 To determine the scale of root architectural constraints and selective pressures on the 252 uptake efficiency of resources with different mobility, root spatial aggregation (L253 function) was calculated at two scales: $t=2 \mathrm{~mm}$ and $t=1 \mathrm{~cm}$ (Fig. S1), corresponding 254 respectively to the spatial scales of root depletion zones for less mobile (e.g. phosphate) 255 and more mobile (e.g. nitrate) ions (de Kroon, Mommer, \& Nishiwaki, 2003).

To assess how the roots of two species in mixtures were positioned in relation to each other, bivariate $\mathrm{L}$ functions ( $\mathrm{Lbv}$ ) were calculated at two spatial scales $(2 \mathrm{~mm}$ and $1 \mathrm{~cm})$, where the bivariate $\mathrm{K}$ function is the expected number of roots belonging to species 1 within a distance $t$ of an arbitrary root belonging to species 2 , divided by the overall root density of species 1 and corrected for edge effects. To account for variable root densities across the observation area, the inhomogeneous version of the bivariate L function was calculated as described above (function Ldot.inhom in R package spatstat). Lbv is zero if the roots of the two species are distributed randomly in relation to each other, negative if roots are segregated, and positive if roots of one species aggregate with roots of the other species (Fig. 1).

Home range size and overlap

270 Three metrics were calculated to describe the spatial extent of whole root systems and 271 overlap between the root systems of focal and neighbouring plants (Fig. 1). Minimum 272 convex polygon (MCP) area was used to describe the home range, i.e. the total area 273 encompassed by roots. The core foraging area was defined as the $50 \%$ kernel area based 274 on the bivariate normal kernel method (Worton, 1989), where a two-dimensional 275 probability density function describes the probability of finding roots in a given area 
within a home range. Home range overlap in species mixtures was calculated as the total

277 kernel volume overlap (expressed as a proportion, with the maximum of 1 in case of 278 complete overlap). Ranges were calculated using package adehabitatHR in R (Calenge, 279 2006).

\section{Statistical analysis}

Linear mixed models were used to estimate the effects of focal species (or species pair identity in analyses of species mixtures; fixed factor, eight levels), neighbour density 284 (fixed factor, continuous variable), soil depth (fixed factor, two levels) and their 285 interactions on root spatial patterns. Pot identity was included as a random factor in all 286 models (as each pot was measured at two soil depths). The following spatial characteristics were examined as response variables: a) L function in species 288 monocultures or species mixtures (focal plants and neighbours separately); and in 289 species mixtures b) bivariate L function ( $\mathrm{Lbv}_{b v}$; c) MCP range of the focal plant; d) core 290 foraging area of the focal plant; and e) kernel volume overlap between focal and 291 neighbour plants. For L functions, separate models were performed for each spatial 292 scale $(2 \mathrm{~mm}$ and $1 \mathrm{~cm}$ ). Models were performed using package lme4 in R (Bates, 293 Mächler, Bolker, \& Walker, 2015).

294 To illustrate the results of linear mixed models, linear models were performed for 295 each species, treatment (species monoculture or mixture) and soil depth combination 296 with neighbour density as a continuous predictor and one of the spatial characteristics 297 described above as a response variable. In the absence of significant interactions 298 between species identity and neighbour density, predicted values at mean neighbour 299 density (four neighbours) were used to illustrate interspecific differences in spatial 
patterns; otherwise, the estimated slope of the relationship between a spatial characteristic and neighbour density was used to illustrate the effect of neighbour density on each focal species.

We used data on plant shoot and root biomass, root tissue density, root branching frequency, root diameter and specific root length from Semchenko et al. (2018) to examine relationships between root spatial patterns and the size and morphological traits of focal plants, as well as trait differences between focal and neighbouring plants, which may reflect differences in competitive abilities or resource acquisition strategies. For each focal species trait, predicted values at the mean neighbour density (four neighbours) were extracted from a linear model with the trait as a response variable and neighbour density as a continuous predictor. In addition, absolute differences between focal and neighbour trait values were calculated for each pot in species mixtures, and predicted absolute trait differences at the mean neighbour density were extracted from linear models as described above. For shoot and root biomass, the absolute difference between the focal plant mass and the total mass of all neighbours in a pot was calculated.

In species monocultures, Pearson's correlations were examined between predicted trait values and L function estimates. In the species mixtures, correlations were examined between predicted trait values of the focal plant and range size (MCP and core), and focal plant L function estimates. Lastly, correlations between absolute trait differences (between the two species in the mixture) and home range overlap, and bivariate $\mathrm{L}$ function $\left(\mathrm{L}_{\mathrm{bv}}\right)$, were examined.

All data analyses were performed in R 3.6.3 (R Core Team, 2020).

\section{Results}


Patterns of root spatial distribution varied significantly as a function of species identity, soil depth and neighbour density and were dependent on the spatial scale of observations (Table 1). At the finest $(2 \mathrm{~mm})$ spatial scale, roots were generally significantly aggregated at the mean neighbour density (four neighbours) but varied widely between species, and the monoculture of Lotus corniculatus exhibited random spatial distribution (Fig. 2a). At the scale of $1 \mathrm{~cm}$, roots were overall less aggregated than at the $2 \mathrm{~mm}$ scale (Fig. 2b). Spatial aggregation patterns were consistent across soil depths except for Sesleria caerulea, which showed significantly less root aggregation at $10 \mathrm{~cm}$ than $5 \mathrm{~cm}$ depth (depth by species interaction in Table 1, Fig. 2a). Root aggregation generally declined with increasing neighbour density at the scale of $2 \mathrm{~mm}$ Fig. 3a, Fig. S2a), but no significant effect of neighbour density was detected at the scale of $1 \mathrm{~cm}$ (Table 1$)$.

\section{Root spatial patterns, range size and overlap in species mixtures}

Spatial aggregation of roots in species mixtures varied strongly between species pairs, with S. caerulea showing most aggregated patterns and L. corniculatus nearly random root distribution at mean neighbour density (Table 1, Fig. 2c-d). Contrary to species monocultures, focal plants in species mixtures exhibited increased root aggregation with neighbour density at $2 \mathrm{~mm}$ spatial scale (Table 1, Figs. $3 \mathrm{~b}$ and S2).

Intraspecific aggregation in neighbouring plants also varied significantly between species mixtures (Table 1, Fig. 2e-f). Small-scale root aggregation in S. caerulea, which was used as the neighbouring species in five species mixtures, differed significantly between mixtures, with aggregation being significantly lower when grown in mixture 
with Carlina vulgaris and Pimpinella saxifraga than when grown with the other three increasing neighbour density (Figs. 2e and 3c), though these effects varied among species, particularly at the $1 \mathrm{~cm}$ spatial scale (Table 1, Figs. $2 \mathrm{f}$ and S2).

Analysis of bivariate spatial patterns revealed that the roots of several species were strongly aggregated in relation to each other at the $2 \mathrm{~mm}$ spatial scale (Fig. $2 \mathrm{~g}$ ). At mean neighbour density, strong aggregation was observed in four species mixtures, while three species combinations showed weaker aggregation or nearly random distribution (Fig. 2g). Aggregation slightly declined with neighbour density (Table 1, Fig. 3d). At the larger spatial scale, interspecific root aggregation was reduced and roots in the mixture of F. vulgaris and $S$. caerulea became significantly segregated (Fig. $2 \mathrm{~h}$ ). Aggregation patterns were consistent across soil depths (Fig. 2g-h).

Focal plant core areas did not significantly shrink with increasing neighbour density, while MCP ranges declined in Antennaria dioica and $S$. caerulea but not other species (significant species by density interaction for MCP range in Table 2, Fig. 4a-b and S3). These two focal species experienced a slight decline in home range overlap with increasing neighbour density, while the other focal species showed increased overlap (Fig. 4c and S3). Core area size and the extent of home range overlap generally increased with soil depth (Table 2, Fig. S3).

\section{Relationship between root spatial patterns and plant traits}

In species monocultures, root spatial aggregation was not significantly related to the total density of roots in soil but was significantly negatively correlated with root diameter at both spatial scales (Fig. 5a, Table S1). In species mixtures, focal plant roots were less aggregated at $2 \mathrm{~mm}$ spatial scale and occupied a larger range if the focal plant 
374 attained high shoot and root biomass and high root density (Table S1, Fig. 5b-d). 375 Interspecific root aggregation (based on bivariate L-function) was negatively correlated 376 with the absolute difference in shoot mass between focal and neighbour plants (Table 377 S1, Fig. 5e). Range volume overlap was positively correlated with the absolute difference 378 between biomass and root density of focal and neighbour plants (Table S1, Fig. 5f).

\section{Discussion}

In this study, we obtained fine-scale measurements of root spatial distributions in a range of grassland species and employed analytical approaches used in animal

383 behavioural studies to describe the foraging efficiency and home range behaviour of 384 plant roots. We found that plant species varied widely in their ability to secure a large 385 belowground home range and position their roots efficiently in space, representing new 386 axes of variation in plant strategies that can have important consequences for species 387 competitive ability, co-existence and efficiency of nutrient uptake. We also demonstrate 388 that roots belonging to different species often aggregated in each other's vicinity at very 389 fine spatial scales, which may represent resource contest at the expense of foraging 390 efficiency. In agreement with theoretical models of animal behaviour (Stamps \& 391 Krishnan, 2001; Morrell \& Kokko, 2005), such contests were more prevalent in 392 interactions between species of similar size while species pairs with asymmetric sizes 393 showed reduced confrontation. These findings suggest that complex evolutionary 394 models of behaviour are applicable to plants and should be considered as mechanisms 395 that can contribute to the effects of biodiversity on resource use efficiency and 396 productivity. 

be combined with additional measurements to further explore the complexity of the 400 phenomenon. First, the species used in this study originate from calcareous grasslands 401 on thin soil and are characterised by slow growth and frequent experience of root 402 growth restriction in stony substrate. As such, they were well suited for a pot 403 experiment, where pot walls may restrict root growth. Pot walls may nonetheless have 404 affected the maximum extent of root systems, particularly for plants grown in the 405 absence of competitors. As a result, the response of focal root systems to neighbour 406 density may have been underestimated. Root morphology may also be affected by 407 interactions with pot walls (Semchenko et al., 2007a, Semchenko, Zobel, Heinemeyer, \& 408 Hutchings, 2008). We therefore restricted our observations to the central area of the pot 409 and left areas adjacent to the pot walls as buffer zones. However, it is also conceivable 410 that roots that were not in direct contact with the pot walls were also affected. Such 411 effects might be particularly problematic for many species of larger size and those that 412 occupy more productive soils. It may therefore be critical to record root spatial 413 positioning under natural, field conditions. Second, in this study, all roots were included 414 in the assessment of spatial patterns. However, roots are likely to vary widely in their 415 physiological activity and may serve the function of nutrient uptake or transport. More 416 detailed knowledge of the costs and benefits of root positioning could be obtained if root 417 positioning were recorded in a time series, preferably over several growth seasons, and 418 combined with a technique enabling the estimation of physiological activity, e.g. 419 enzymatic activity (Razavi, Zarebanadkouki, Blagodatskaya, \& Kuzyakov, 2016). 
The roots of most species were aggregated at fine spatial scales, likely reflecting fundamental constraints on root architecture. Aggregation declined with increasing spatial scale suggesting that plant root systems are less developmentally constrained and able to occupy space more evenly at larger spatial scales. Wide variation in the levels of aggregation was observed between species. Contrary to modelling studies predicting that large root systems should be less efficient in root spatial positioning (Berntson, 1994; Pagès, 2011), variation observed in this study could not be explained by total root density. We found that species exhibiting lower levels of root aggregation were characterised by larger root diameters. Large root diameter may reflect high root construction costs as well as strong dependence on mycorrhizal associations, as a thicker cortex layer offers space for fungal colonisation (Cortois, Schroder-Georgi, Weigelt, van der Putten, \& De Deyn, 2016; Kong et al., 2019; Bergmann et al., 2020). Therefore, it may be that species with more costly roots experience stronger selective pressure to position their roots efficiently in soil, even if such roots primarily play the role of transport and nutrient exchange with fungal partners. However, this relationship is only correlative and based on eight species, and hence requires further exploration across a wider range of species and environmental conditions.

We found that root spatial aggregation in species monocultures (as well as interspecific aggregation in species mixtures) tended to decline with increasing neighbour density. This indicates that having more individuals per unit soil surface area could be an important driver of efficient soil exploration, and ecological processes that reduce plant mortality may significantly modify plant community functioning and resource use efficiency. For example, niche complementarity or dilution of natural enemy pressure in more diverse plant communities could support higher densities of individuals (Peters, 2003; Marquard et al., 2009), which in turn could improve nutrient 
foraging and transport efficiency, with potential positive effects on community

448

449

450

451

452

453

454

455

456

457

458

459

460

461

462

463

464

465

466

467

468

469

470 productivity.

Root spatial patterns and range overlap in species mixtures

We found that several species mixtures exhibited high levels of interspecific aggregation at very fine spatial scales. Positioning roots very close to a competitor's roots may reduce resource uptake efficiency but may intensify competition and thus represent a contest of resources. Theoretical models of behaviour predict that interactions between players with symmetric competitive abilities are likely to lead to escalated fights while asymmetric interactions lead to reduced contest (Stamps \& Krishnan, 2001; Novoplansky, 2009). In line with these predictions, we found that interspecific root aggregation was particularly pronounced in mixtures of species with similar biomass, indicating similar competitive abilities (Keddy, Nielsen, Weiher, \& Lawson, 2002; Wang et al., 2010; Semchenko et al., 2018). In mixtures composed of species with very different sizes, the home range of the larger competitor encompassed most of the range of the inferior competitor. However, low levels of interspecific root aggregation were observed despite the clear opportunity for contest. This observation is consistent with an evolutionary model of root biomass production where in combinations of competitors with contrasting competitive abilities it becomes obsolete for the superior competitor to "harass" the weaker neighbour by producing extra roots, and the weaker competitor curtails its root production in the face of a contest that could not be won (McNickle \& Brown, 2012).

Species mixtures differed significantly in how the roots of different species were positioned in relation to each other but also how roots belonging to the same species 
471 (intraspecific aggregation) were affected by the presence of other species. Aggregation

472 within individual focal root systems tended to increase with the increasing density of

473 heterospecific competitors. Such a response to increasing competitive pressure may

474 represent a strategy of consolidating occupied space and preventing further intrusion by 475 heterospecific roots, even if it comes at the cost of increased intraplant competition. It 476 could be achieved by switching from shallow rooting angles (most effective for avoiding 477 intraplant competition) to deeper angles that reduce root system overlap between 478 neighbours (Ge et al., 2000; Rubio, 2001). In line with this interpretation, we found that 479 home ranges declined in some species, while core area size remained stable, with 480 increasing neighbour density, suggesting that plants held on to their core foraging areas 481 but ceded space at the limits of their ranges with increasing competitive pressure.

Besides the density of competitors, the species identity of competitors also 483 significantly modified root placement. In our study, we created species mixtures by 484 coupling focal plants with neighbours that they encountered most frequently in the field. 485 This resulted in using one of the dominant grass species as the neighbouring species in 486 five mixtures. The root placement of this species was highly responsive to the identity of 487 the focal species. The grass showed highly aggregated root placement when combined 488 with three species but intraspecific root aggregation was much lower in other two 489 mixtures (levels similar to those observed in monoculture conditions). These 490 observations indicate that the efficiency of root placement differs significantly between 491 species but is also highly plastic within species in response to the density and identity of 492 competitors.

\section{Conclusions}


Fine-scale root spatial mapping can be combined with different statistical approaches to

495 gain new insights into plant belowground strategies and test the applicability to plants of animal-based behavioural theories. The majority of game-theoretic models of plant behaviour to date have focussed on predicting root biomass production over large spatial scales. Here we go beyond assessing root biomass production and highlight the importance of considering the spatial distribution of individual roots. Our study uncovered a diverse range of ways plants deploy their roots in space. New modelling approaches are now needed to explore which spatial strategies are evolutionarily stable in the presence of competitors with different characteristics and why. We found that the efficiency of root placement depended on the density and species identity of interacting plants as well as their relative size. Therefore, community processes that determine plant mortality and species richness and composition may play an important role in regulating plant behavioural responses and associated efficiency of soil exploitation. Finally, there were no clear links between spatial patterns and commonly measured root morphological traits, indicating that root placement strategies may represent a distinct trait axis that can significantly expand our understanding of plant belowground strategies.

\section{Acknowledgements}

We thank Aime Randveer, Sirgi Saar and Siim-Kaarel Sepp for help in planting, harvesting and measuring plants, and the reviewers and the editor for their valuable suggestions. This work was supported by Estonian Science foundation (grants 9332 and 9269), Institutional Research Funding (IUT 20-28 and IUT 20-31) of the Estonian 
518 of Excellence EcolChange). MS has been supported by the Research Fellowship awarded 519 by the University of Manchester. 


\section{References}

521 Adams, E.S. (2001). Approaches to the study of territory size and shape. Annual Review of Ecology, Evolution and Systematics, 32, 277-303.

523

524

525

526

527

528

529

530

531

532

533

534

535

536

537

538

539

540

541

542

543

Almeida, C.S., Cristaldo, P.F., Desouza, O.G., Bacci, L., Florencio, D.F., Cruz, N.G.,...Araújo, A.P.A. (2018). Resource density regulates the foraging investment in higher termite species. Ecological Entomology, 43, 371-378.

Baddeley, A., Rubak, E., Turner, R. (2015). Spatial Point Patterns: Methodology and Applications with R. Chapman and Hall/CRC Press, London.

Bardgett, R.D., Mommer, L. \& De Vries, F.T. (2014). Going underground: root traits as drivers of ecosystem processes. Trends in Ecology and Evolution, 29, 692-699.

Bates, D., Mächler, M., Bolker, B.M. \& Walker, S.C. (2015). Fitting linear mixed-effects models using lme4. Journal of Statistical Software, 67, 1-48.

Bergmann, J., Weigelt A., van der Plas, F., Laughlin, D.C., Kuyper, T.W., Guerrero-Ramirez, N., ... Mommer, L. (2020). The fungal collaboration gradient dominates the root economics space in plants. Science Advances, 6, eaba3756.

Berntson, G.M. (1994). Modelling root architecture: are there tradeoffs between efficiency and potential of resource acquisition? New Phytologist, 127, 483-493.

Börger, L., Dalziel, B.D. \& Fryxell, J.M. (2008). Are there general mechanisms of animal home range behaviour? A review and prospects for future research. Ecology Letters, 11, 637-650.

Brisson, J. \& Reynolds, J.F. (1994). The effect of neighbours on root distribution in a creosotebush (Larrea tredentata) population. Ecology, 75, 1693-1702.

Cahill, J.F., McNickle, G.G., Haag, J.J., Lamb, E.G., Nyanumba, S.M. \& St. Clair, C.C. (2010). Plants integrate information about nutrients and neighbors. Science, 328, 1657. 
544 Caldwell, M.M., Manwaring, J.H. \& Durham, S.L. (1991). The microscale distribution of neighbouring plant roots in fertile soil microsites. Functional Ecology, 5, 765-772.

Caldwell, M.M., Manwaring, J.H. \& Durham, S.L. (1996). Species interactions at the level of fine roots in the field: Influence of soil nutrient heterogeneity and plant size. Oecologia, 106, 440-447.

Calenge, C. (2006). The package "adehabitat" for the R software: A tool for the analysis of space and habitat use by animals. Ecological Modelling, 197, 516-519.

Carpenter, F.L. (1987). Food abundance and territoriality: to defend or not to defend? American Zoologist, 27, 387-399.

Cortois, R., Schroder-Georgi, T., Weigelt, A., van der Putten, W.H. \& De Deyn, G.B. (2016). Plant-soil feedbacks: role of plant functional group and plant traits. Journal of Ecology, 104, 1608-1617.

De Kroon, H., Mommer, L. \& Nishiwaki, A. (2003). Root competition: towards a mechanistic understanding. In Root Ecology (pp. 215-234). Springer, Berlin, Heidelberg.

Dunbabin, V., Rengel, Z. \& Diggle, A.J. (2004). Simulating form and function of root systems: efficiency of nitrate uptake is dependent on root system architecture and. Functional Ecology, 18, 204-211.

Fitter, A.H. (1987). An architectural approach to the comparative ecology of plant-root systems. New Phytologist, 106, 61-77.

Fitter, A.H., Stickland, T.R., Harvey, M.L. \& Wilson, G.W. (1991). Architectural analysis of plant root systems 1. Architectural correlates of exploitation efficiency. New Phytologist, 118, 375-382.

Ge, Z., Rubio, G. \& Lynch, J.P. (2000). The importance of root gravitropism for inter-root competition and phosphorus acquisition efficiency: results from a geometric 
570 Gersani, M., Abramsky, Z., \& Falik, O. (1998). Density-dependent habitat selection in plants. Evolutionary Ecology, 12, 223-234.

572 Gersani, M., Brown, J.S., O’Brien, E.E., Maina, G.M. \& Abramsky, Z. (2001). Tragedy of the 573 commons as a result of root competition. Jpurnal of Ecology, 89, 660-669.

574 Holzapfel, C. \& Alpert, P. 2003. Root cooperation in a clonal plant: connected 575 strawberries segregate roots. Oecologia, 134, 72-7.

Keddy, P., Nielsen, K., Weiher, E. \& Lawson, R. (2002). Relative competitive performance of 63 species of terrestrial herbaceous plants. Journal of Vegetation Science, 13, 516.

Kong, D.L., Wang, J.J., Wu, H.F., Valverde-Barrantes, O.J., Wang, R.L., Zeng, H. ... Feng, Y. (2019). Nonlinearity of root trait relationships and the root economics spectrum. Nature Communications, 10, 2203.

Kramer-Walter, K.R., Bellingham, P.J., Millar, T.R., Smissen, R.D., Richardson, S.J. \& Laughlin, D.C. (2016). Root traits are multidimensional: specific root length is independent from root tissue density and the plant economic spectrum. Journal of Ecology, 104, 1299-1310.

Kreyling, J., Schweiger, A.H., Bahn, M., Ineson, P., Migliavacca, M., Morel-Journel, T. ... Larsen, K. S. (2018). To replicate, or not to replicate - that is the question: how to tackle nonlinear responses in ecological experiments. Ecology Letters, 21, 16291638.

Laclau, J.-P., Nouvellon, Y., Reine, C., Gonçalves, J.L. de M., Krushe, A.V., ... Bouillet, J-P. (2013). Mixing Eucalyptus and Acacia trees leads to fine root over-yielding and vertical segregation between species. Oecologia, 172, 903-913.

Lang, C., Dolynska, A., Finkeldey, R. \& Polle, A. (2010). Are beech (Fagus sylvatica) roots 
595

596

597

598

599

600

601

602

603

604

605

606

607

608

609

610

611

612

613

614

615

616

617

618

Ljubotina, M. K. \& Cahill, J. F. (2019). Effects of neighbour location and nutrient distributions on root foraging behaviour of the common sunflower. Proceedings of the Royal Society B-Biological Sciences, 286, 20190955.

Lynch, J.P. \& Brown, K.M. (2001). Topsoil foraging - an architectural adaptation of plants to low phosphorus availability. Plant and Soil, 237, 225-237.

Mahall, B.E. \& Callaway, R.M. (1991). Root communication among desert shrubs. Proceedings of the National Academy of Sciences of the USA, 88, 874-876.

Mahall, B.E. \& Callaway, R.M. (1992). Root communication mechanisms and intracommunity distributions of two Mojave Desert shrubs. Ecology, 73, 21452151.

Maina, G.G., Brown, J.S. \& Gersani, M. (2002). Intra-plant versus inter-plant root competition in beans: avoidance, resource matching or tragedy of the commons. Plant Ecology, 160, 235-247.

Mamolos, A.P., Elisseou, G.K. \& Veresoglou, D.S. (1995). Depth of root activity of coexisting grassland species in relation to $\mathrm{N}$ and $\mathrm{P}$ additions, measured using nonradioactive tracers. Journal of Ecology, 83, 643-652.

Marquard, E., Weigelt, A., Roscher, C., Gubsch, M., Lipowsky, A. \& Schmid, B. (2009). Positive biodiversity-productivity relationship due to increased plant density. Journal of Ecology, 97, 696-704.

McNickle, G.G. \& Brown, J.S. (2012). Evolutionarily stable strategies for nutrient foraging and below-ground competition in plants. Evolutionary Ecology Research, 14, 667687.

McNickle, G.G. \& Brown, J.S. (2014). An ideal free distribution explains the root production of plants that do not engage in a tragedy of the commons game. Journal 
of Ecology, 102, 963-971.

Mommer, L., Van Ruijven, J., De Caluwe, H., Smit-Tiekstra, E.A., Wagemaker, A.M.C., Joop, N.O., ... de Kroon, H. (2010). Unveiling below-ground species abundance in a biodiversity experiment: a test of vertical niche differentiation among grassland species. Journal of Ecology, 98, 1117-1127.

Morrell, L.J. \& Kokko, H. (2005). Bridging the gap between mechanistic and adaptive explanations of territory formation. Behavioral Ecology and Sociobiology, 57, 381390.

Nettan, S., Thetloff, M., Lepik, A., Semchenko, M. \& Zobel, K. (2019). Manipulation of vegetation with activated carbon reveals the role of root exudates in shaping native grassland communities. Journal of Vegetation Science, 30, 1056-1067.

Novoplansky, A. (2009). Picking battles wisely: plant behaviour under competition. Plant, Cell and Environment, 32, 726-741.

O’Brien, E.E., Brown, J.S. \& Moll, J.D. (2007). Roots in space: a spatially explicit model for below-ground competition in plants. Proceedings of the Royal Society B-Biological Sciences, 274, 929-934.

Pagès, L. (2011). Links between root developmental traits and foraging performance. Plant, Cell and Environment, 34, 1749-1760.

Pärtel, M., Kalamees, R., Zobel, M. \& Rosen, E. (1999). Alvar grasslands in Estonia: variation in species composition and community structure. Journal of Vegetation Science, $10,561-570$.

Peters, H.A. (2003). Neighbour-regulated mortality: the influence of positive and negative density dependence on tree populations in species-rich tropical forests. Ecology Letters, 6, 757-765.

Ravenek, J. M., Mommer, L., Visser, E. J. W., van Ruijven, J., van der Paauw, J. W., Smit- 
Tiekstra, A., ... de Kroon, H. (2016). Linking root traits and competitive success in grassland species. Plant and Soil, 407, 39-53.

Razavi, B.S., Zarebanadkouki, M., Blagodatskaya, E. \& Kuzyakov, Y. (2016). Rhizosphere shape of lentil and maize: Spatial distribution of enzyme activities. Soil Biology and Biochemistry, 96, 229-237.

R Core Team (2020). R: A language and environment for statistical computing. R Foundation for Statistical Computing, Vienna, Austria.

Ripley, B.D. (1976). The second-order analysis of stationary point processes. Journal of Applied Probability, 13, 255-266.

Robinson, D., Hodge, A. \& Fitter, A. (2003). Constraints on the form and function of root systems. In: de Kroon, H., Visser, E.J.W., eds. Root Ecology. Berlin, Germany: Springer Berlin Heidelberg, 1-31.

Roumet, C., Birouste, M., Picon-Cochard, C., Ghestem, M., Osman, N., Vrignon-Brenas, S., ... Stokes, A. (2016). Root structure-function relationships in 74 species: evidence of a root economics spectrum related to carbon economy. New Phytologist, 210, 815826.

Rowlingson, B. \& Diggle, P. (2017). Splancs: spatial and space-time point pattern analysis. R package version 2.01-40.

Rubio, G. (2001). Root gravitropism and below-ground competition among neighbouring plants: a modelling approach. Annals of Botany, 88, 929-940.

Schenk, H.J., Callaway, R.M. \& Mahall, B.E. (1999). Spatial root segregation: are plants territorial? In: Fitter, A.H. \& Raffaelli, D., eds. Advances in ecological research. Academic Press, 145-180.

Semchenko, M., Abakumova, M., Lepik, A. \& Zobel, K. (2013). Plants are least suppressed by their frequent neighbours: the relationship between competitive ability and 
670 Semchenko, M., Hutchings, M.J. \& John, E.A. (2007a). Challenging the tragedy of the 671 commons in root competition: confounding effects of neighbour presence and 672 substrate volume. Journal of Ecology, 95, 252-260.

673 Semchenko, M., John, E.A. \& Hutchings, M.J. (2007b). Effects of physical connection and 674 genetic identity of neighbouring ramets on root-placement patterns in two clonal species. New Phytologist, 176, 644-54.

676

Semchenko, M., Lepik, A., Abakumova, M. \& Zobel, K. (2018). Different sets of belowground traits predict the ability of plant species to suppress and tolerate their competitors. Plant and Soil, 424, 157-169.

Semchenko, M., Zobel, K., Heinemeyer, A. \& Hutchings, M. J. (2008). Foraging for space and avoidance of physical obstructions by plant roots: a comparative study of grasses from contrasting habitats. New Phytologist, 179, 1162-1170.

Sih, A. \& Mateo, J. (2001). Punishment and persistence pay: a new model of territory establishment and space use. Trends in Ecology and Evolution, 16, 477-479.

Stamps, J.A. \& Krishnan, V.V. (2001). How territorial animals compete for divisible space: a learning-based model with unequal competitors. American Naturalist, 157, 154169.

Traniello, J.F.A. (1989). Foraging strategies of ants. Annual Review of Entomology, 34, 191-210.

Wang, P., Stieglitz, T., Zhou, D.W. \& Cahill Jr, J.F. (2010). Are competitive effect and response two sides of the same coin, or fundamentally different? Functional Ecology, 24, 196-207.

Worton, B.J. (1989). Kernel methods for estimating the utilization distribution in homerange studies. Ecology, 70, 164-168. 
694 Yang, X. F., Li, L. L., Xu, Y. \& Kong, C. H. (2018). Kin recognition in rice (Oryza sativa) $695 \quad$ lines. New Phytologist, 220, 567-578. 
697

698 Table 1. Results of linear mixed models examining the effects of species or species pair 699 identity, neighbour density and soil depth on root spatial distribution (L-function) in 700 species monocultures, intraspecific root distribution of focal (focal L-function) and 701 neighbouring plants (neigh L-function) and interspecific root association in species 702 mixtures (bivariate L-function). Rooting patterns were examined at two spatial scales (2 $703 \mathrm{~mm}$ and $1 \mathrm{~cm}$ ). F-values and their significance are shown. $\$ \mathrm{P}<0.1{ }^{*} P<0.05 ;{ }^{* *} P<$ $7040.01 ;{ }^{* * *} P<0.001$. df - degrees of freedom. Residual degrees of freedom are based on 705 Kenward-Roger approximations.

\begin{tabular}{|c|c|c|c|c|c|c|c|c|c|}
\hline & \multicolumn{3}{|c|}{ Monoculture L-function } & \multicolumn{2}{|c|}{ Mixture focal L-function } & \multicolumn{2}{|c|}{ Mixture neigh L-function } & \multicolumn{2}{|c|}{ Bivariate L-function } \\
\hline & $\mathrm{df}$ & $2 \mathrm{~mm}$ & $1 \mathrm{~cm}$ & $2 \mathrm{~mm}$ & $1 \mathrm{~cm}$ & $2 \mathrm{~mm}$ & $1 \mathrm{~cm}$ & $2 \mathrm{~mm}$ & $1 \mathrm{~cm}$ \\
\hline Species (S) & 7 & $15.43 * * *$ & $4.50 * * *$ & $22.30 * * *$ & $6.29 * * *$ & $28.55 * * *$ & $5.54 * * *$ & $30.32 * * *$ & $3.21 * *$ \\
\hline Neighbour density (N) & 1 & $12.23 * * *$ & 0.18 & $4.35 *$ & 2.29 & $4.23 *$ & 0.37 & $4.28 *$ & 0.01 \\
\hline Depth (D) & 1 & 0.11 & 1.82 & 2.30 & 0.65 & $5.30 *$ & 1.17 & $3.50 \$$ & 0.02 \\
\hline $\mathrm{S}: \mathrm{N}$ & 7 & 1.35 & $1.95 \$$ & 1.02 & 0.76 & 0.56 & 1.72 & 0.44 & 0.43 \\
\hline$S: D$ & 7 & $3.07 * *$ & $3.24 * *$ & 1.25 & $1.90 \$$ & 0.22 & $3.03 * *$ & 1.73 & 0.67 \\
\hline$N: D$ & 1 & 0.04 & 0.04 & $<0.01$ & 0.01 & $<0.01$ & 0.10 & $<0.01$ & $<0.01$ \\
\hline $\mathrm{S}: \mathrm{N}: \mathrm{D}$ & 7 & 0.36 & 1.53 & 0.97 & 0.55 & 1.51 & $2.22 *$ & 0.60 & 0.90 \\
\hline Res df & & 106 & & 100 & & 71 & & 71 & \\
\hline
\end{tabular}


707 Table 2. Results of linear mixed models examining the effects of species pair identity, 708 neighbour density and soil depth on the size of focal plant foraging ranges in species 709 mixtures (expressed as minimum convex polygon, MCP or 50\% kernel core area) and 710 home range overlap between focal and neighbour plants in species mixtures (expressed 711 as the overlap between total kernel volumes). F-values and their significance are shown. $712 \$ \mathrm{P}<0.1{ }^{*} P<0.05 ;^{* *} P<0.01$; $^{* *} P<0.001$. df - degrees of freedom. Residual degrees 713 of freedom were 103 for range size models and 73 for range overlap models (based on 714 Kenward-Roger approximations).

\begin{tabular}{lcccc}
\hline & \multicolumn{3}{c}{ Range size } & Range \\
& df & MCP & Core area & $\begin{array}{c}\text { volume } \\
\text { overlap }\end{array}$ \\
\hline Species (S) & 7 & $40.4^{* * *}$ & $30.6^{* * *}$ & $3.2^{* *}$ \\
Neighbour density (N) & 1 & $8.2^{* *}$ & 0.03 & $27.6^{* * *}$ \\
Depth (D) & 1 & 0.07 & $7.2^{* *}$ & $6.0^{*}$ \\
S:N & 7 & $2.5^{*}$ & 0.53 & $3.5^{* *}$ \\
S:D & 7 & 1.2 & 1.8 & $2.1 \$$ \\
N:D & 1 & $4.5^{*}$ & 1.1 & 1.2 \\
S:N:D & 7 & 1.2 & 0.71 & 1.4 \\
\hline
\end{tabular}

715 


\section{Focal: F. vulgaris \\ Neighbour: S. caerulea}
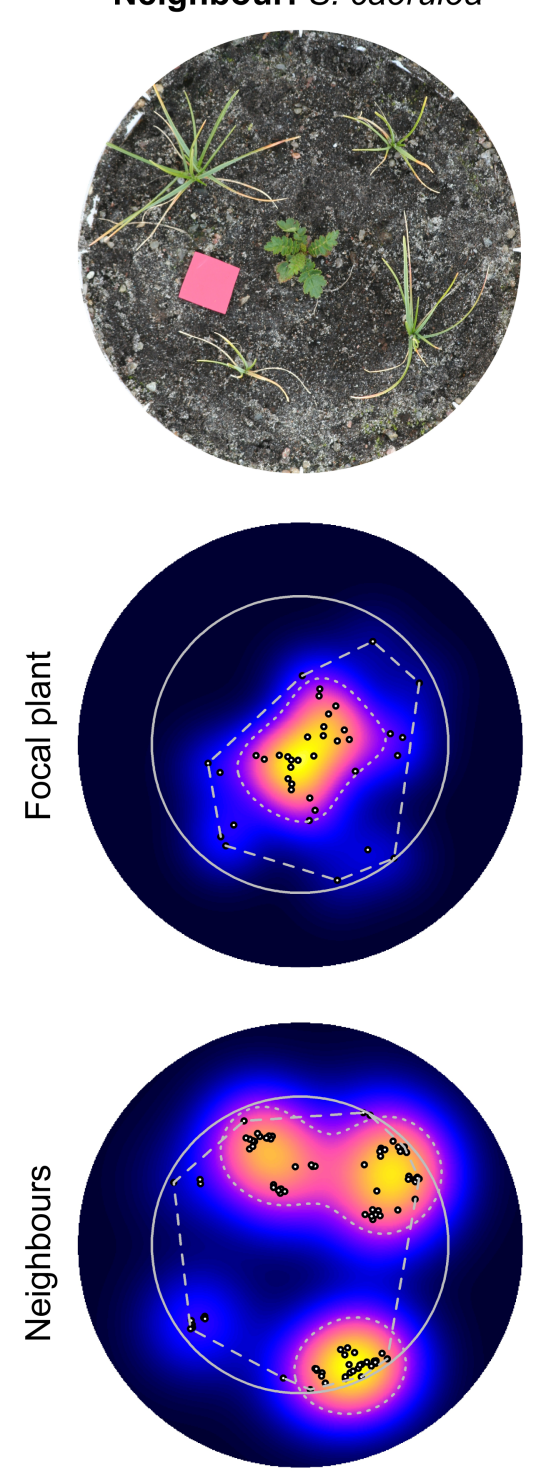

$$
\begin{array}{ll}
2 \mathrm{~mm} & \mathrm{~L}_{\mathrm{f}}=-56.5 \mathrm{~L}_{\mathrm{n}}=226.8 \mathrm{~L}_{\text {bv }}=-28.9 \\
1 \mathrm{~cm} & \mathrm{~L}_{\mathrm{f}}=27.9 \quad \mathrm{~L}_{n}=151.4 \quad \mathrm{~L}_{\text {bv }}=-5.5
\end{array}
$$

\section{Focal: $P$. officinarum \\ Neighbour: S. caerulea}
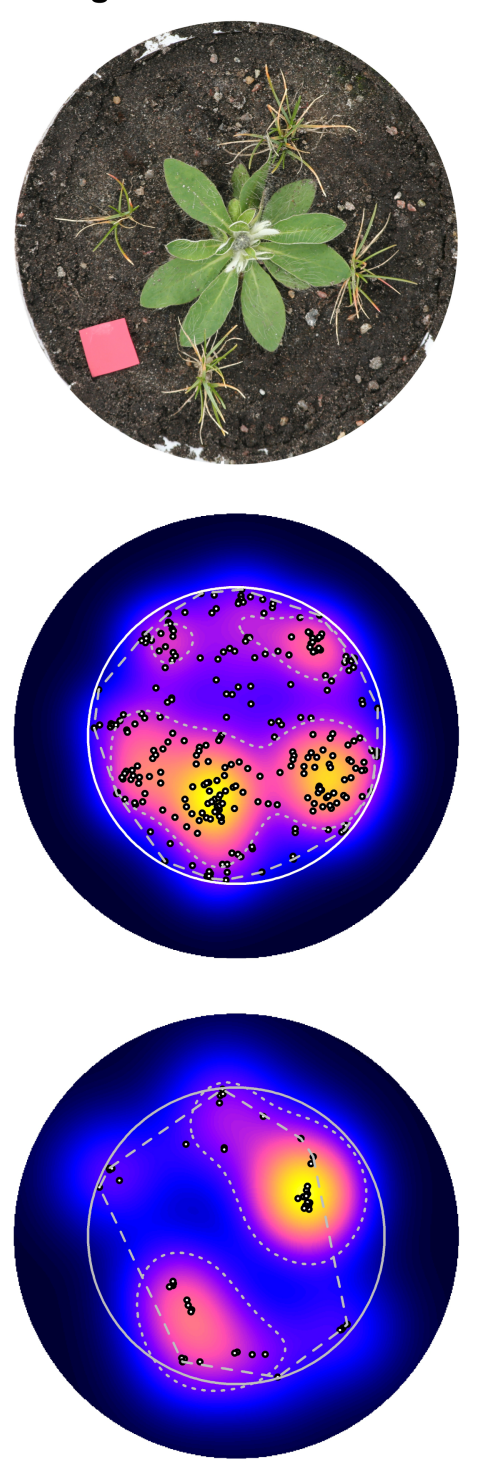

$\begin{array}{ll}L_{f}=50.4 & L_{n}=288.6 L_{b v}=43.3 \\ L_{f}=34.5 & L_{n}=186.7 \\ L_{b v}=20.7\end{array}$

Range overlap $=0.76$

Figure 1. Examples of root spatial distributions in species mixtures with a focal plant located in the centre and four neighbours located at $2 / 3$ of the pot radius from the centre. Yellow colours indicated the highest and dark blue the lowest root densities.

Root locations are shown with grey dots; the solid rings indicate the central area of pots, where root locations were recorded (2/3 of the pot radius); the dashed lines show minimum convex polygon (MCP) home ranges; and dotted lines shows the $50 \%$ kernel 
724 core areas. Roots are less spatially aggregated (as indicated by lower values of the L725 functions) and home range overlap is smaller in the mixture of Filipendula vulgaris and 726 Sesleria caerulea than in the mixture of Pilosella officinarum and Sesleria caerulea. $\mathrm{L}_{\mathrm{f}}, \mathrm{L}_{\mathrm{n}}$ 727 and $L_{b v}$ refer to L-functions for intraspecific root distribution of the focal plant and 728 neighbours and bivariate L-function for interspecific distribution, respectively. 

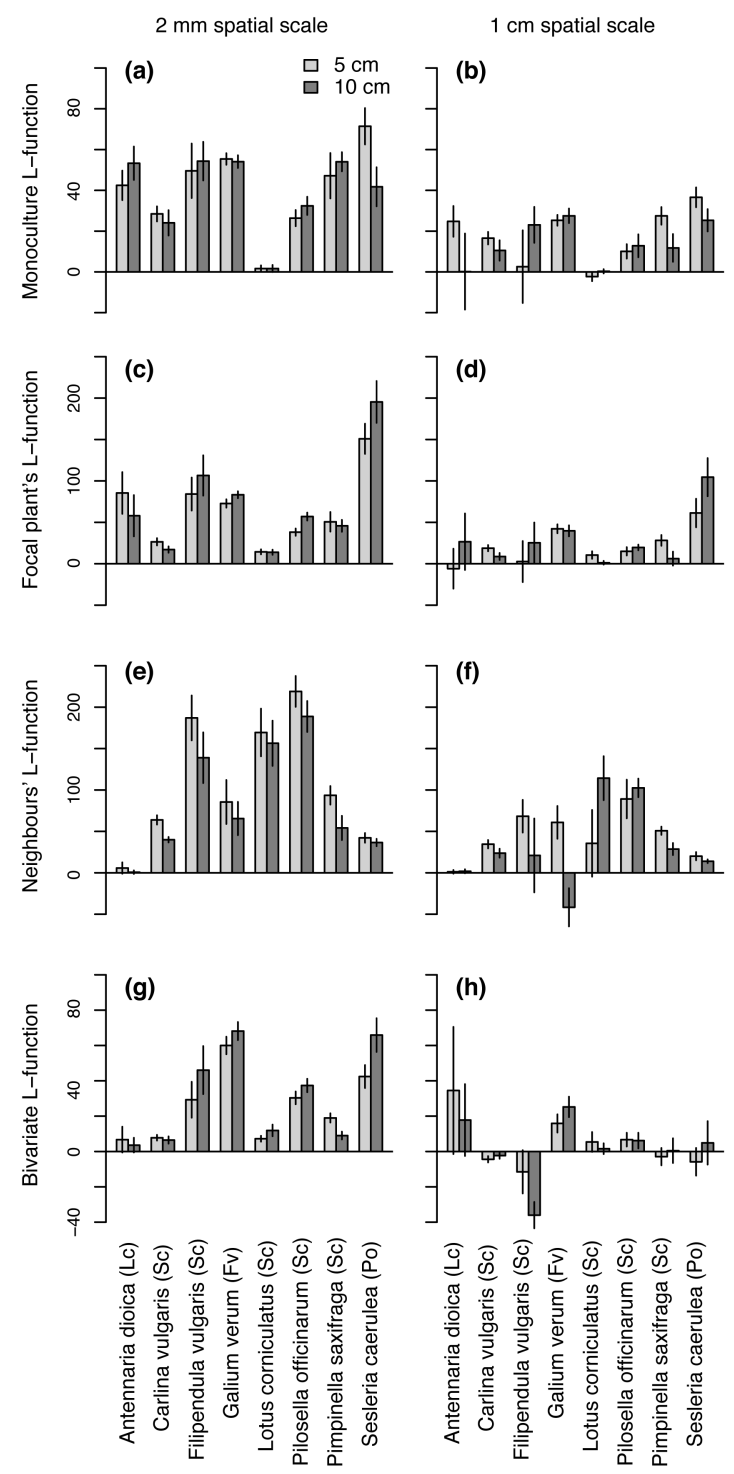

730 Figure 2. Root spatial distribution (L-function) in eight species monocultures (a-b) and 731 mixtures (c-h) at two soil depths $(5 \mathrm{~cm}$ and $10 \mathrm{~cm})$ and two spatial scales $(2 \mathrm{~mm}$ and 1 $732 \mathrm{~cm})$. Intraspecific root distributions of the focal plant (c-d), neighbouring plants (e-f) 733 and interspecific root associations (g-h) calculated as a bivariate L-function are shown. 734 Predicted values \pm SE at the density of four neighbours are shown. Positive values 735 indicate root spatial aggregation and negative values indicate spatial segregation. The names of focal species are shown in full, followed by the abbreviations of neighbouring

737 species in parentheses (Lc - Lotus corniculatus; Sc - Sesleria caerulea; Fv - Filipendula vulgaris, Po - Pilosella officinarum). 

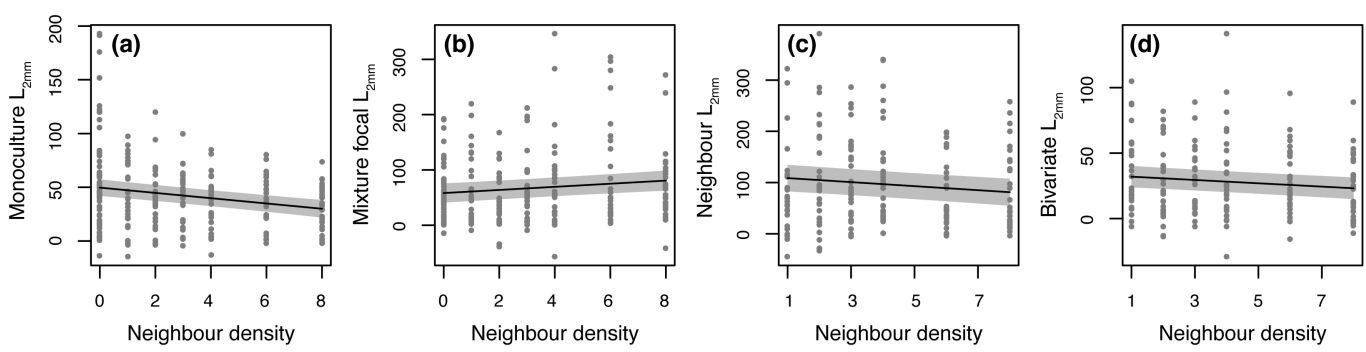

740 Figure 3. Overall effect of neighbour density on root spatial distributions (L-functions)

741 at $2 \mathrm{~mm}$ spatial scale. Intraspecific root distributions of all plants in species

742 monocultures (a), the focal plant (b) and neighbouring plants (c) in species mixtures,

743 and interspecific root associations calculated as a bivariate L-function (d), are shown.

744 Regression lines and 95\% confidence intervals obtained from linear mixed models, with

745 species identity and pot included as random factors, are shown. 

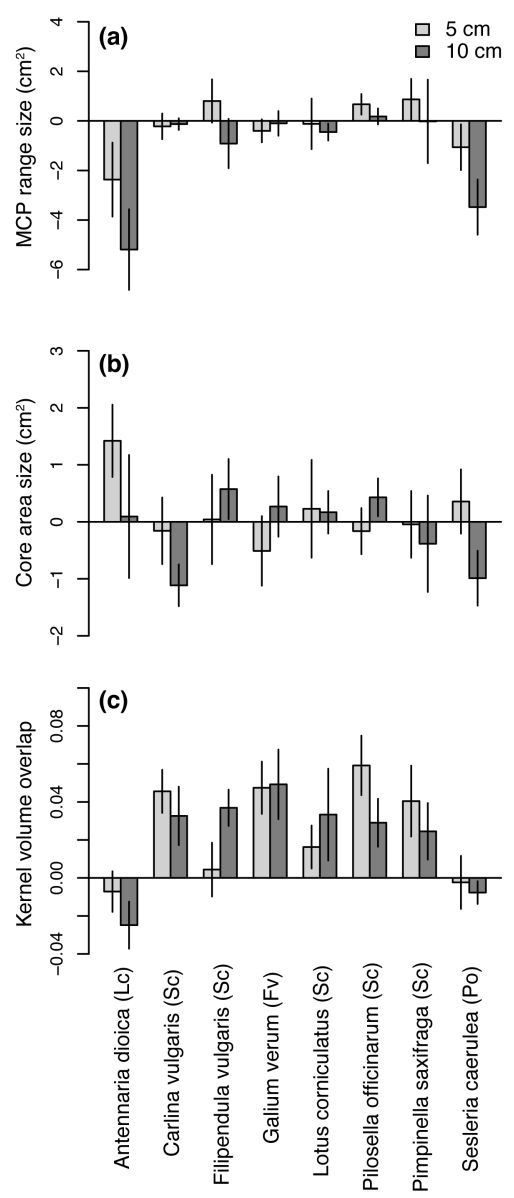

748 Figure 4. Changes in focal plant home range size and overlap with increasing neighbour 749 density in eight species mixtures at two soil depths $(5 \mathrm{~cm}$ and $10 \mathrm{~cm})$. Home ranges were 750 calculated as an area inside a minimum convex polygon (a) or 50\% kernel core area (b). 751 Home range overlap was calculated based on total kernel volume, with the value of 1 752 indicating full overlap (c). Slopes \pm SE from a regression of home range against 753 neighbour density are shown. Positive values indiciate an increase and negative value a 754 decrease in range size or overlap with increasing neighbour density. The names of focal 755 species are shown in full, followed by the abbreviations of neighbouring species in 756 parentheses (Lc - Lotus corniculatus; Sc - Sesleria caerulea; Fv - Filipendula vulgaris, Po 757 - Pilosella officinarum). 

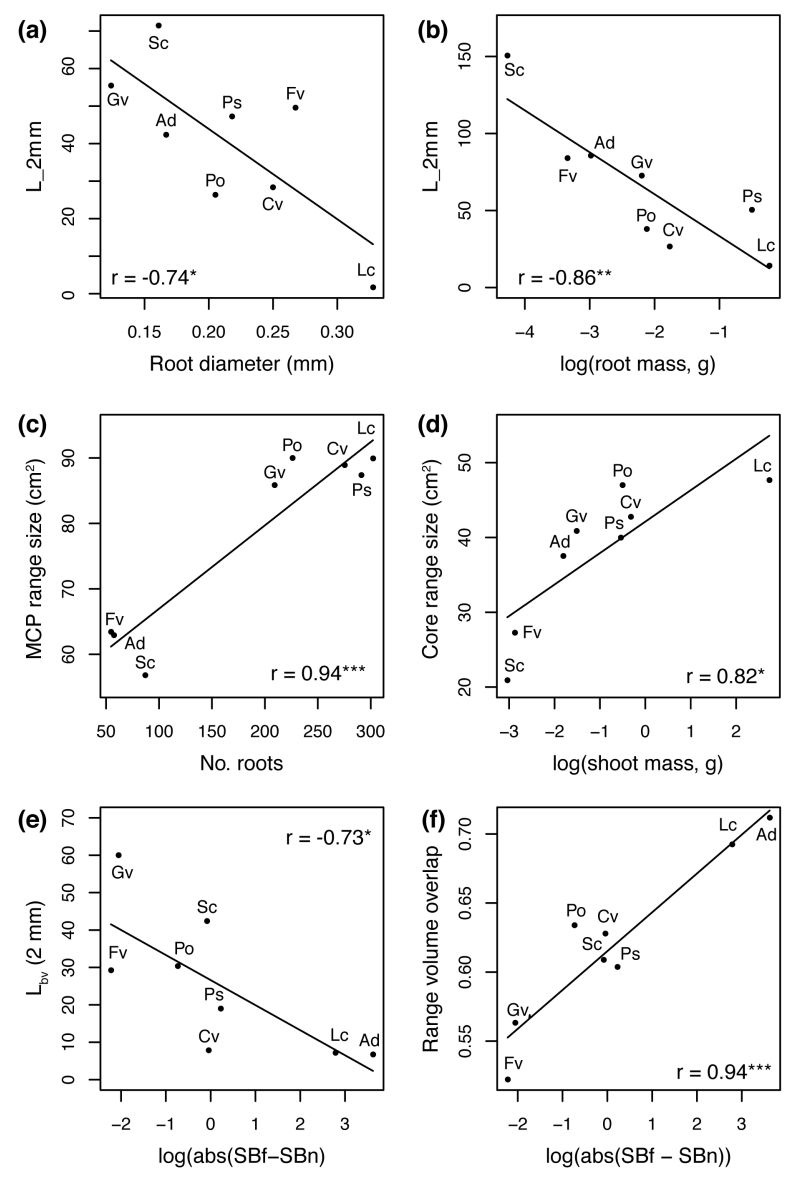

Figure 5. Correlations between root spatial patterns and plant traits. a) Root aggregation at $2 \mathrm{~mm}$ spatial scale in species monocultures and root diameter; b) focal plant's root aggregation at $2 \mathrm{~mm}$ spatial scale and root mass in species mixtures; c)

763 minimum convex polygon home range and total number of roots recorded for the focal plant in species mixtures; d) 50\% kernel core area and shoot mass of focal plants in species mixtures; absolute difference in shoot mass between focal plant and neighbours

766 in species mixtures and e) interspecific root aggregation at $2 \mathrm{~mm}$ spatial scale, 767 calculated as bivariate L-function, and f) total kernel volume overlap. All values 768 represent predicted means at mean neighbour density (four neighbours) at soil depth of

$7695 \mathrm{~cm}$. Focal species names are indicated with initial letters for genus and species names.

770 Pearson correlation coefficients and their significance are shown $(\$ P<0.1, * P<0.05$, *** $P<0.001)$. 